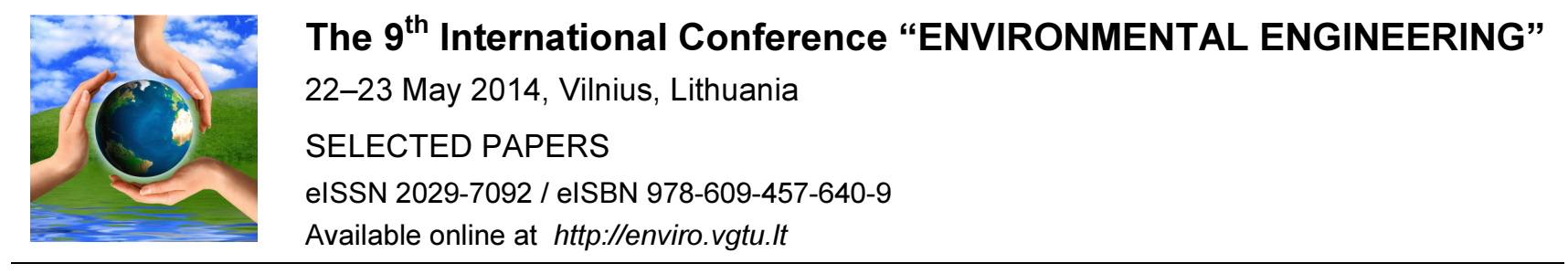

Section: Technologies of Geodesy and Cadastre

\title{
Software automation impact on aerial triangulation accuracy and geometric quality of orthophoto mosaic based on UltraCAM D sample images
}

\author{
Ina Järve, Natalja Liba, Marian Rand, Jaano Berg-Jürgens \\ Estonian University of Life Sciences, Kreutzwaldi 5, Tartu 51014, Estonia
}

\begin{abstract}
The current developments in photogrammetry software enable to obtain more detailed and higher resolution photoproducts in a shorter period of time. In addition to that, digital orthophoto production has become more automated, making the operator's task relatively easy. The present research investigates to which extent software automation affects the accuracy of aerial triangulation and geometric quality of orthophoto mosaic based on digital frame aerial camera UltraCAM D images. For this purpose, two separate projects were carried out: the first project examined the accuracy of aerial triangulation (AT) and the second one the geometric quality of the mosaic. The first project involved making two photo blocks: one with automatic and another with manual AT. In the second project, 3 orthophoto mosaics were made: one with fully automated processing steps for orthophoto production, the second with semi-automated steps with automatic AT and DEM correction, and the third one with manual steps. The Mean Root Square Error (RMS) quality of both projects was analyzed using ground control points.

Both photo blocks of the first project didn't exceed the permitted size (RMS $\leq 0.45 \mathrm{~m}$ ). The geometric accuracy of the manual AT was $0.094 \mathrm{~m}$ and that of the automatic AT was $0.415 \mathrm{~m}$. The analysis of the geometric quality of the mosaics (second project) showed that geometrically the most accurate is the mosaic made with manual processing steps. The RMS was $0.308 \mathrm{~m}$. The RMS of the semiautomatic mosaic was $0.335 \mathrm{~m}$. The full-automatic mosaic was not within the permitted size: its RMS was 1.805 .
\end{abstract}

Keywords: UltraCAM D; orthophoto mosaic; aerial triangulation; digital elevation model; geometrical quality.

\section{Introduction}

Photogrammetry is applied in many areas of life, starting with agriculture and ending with geology and hydrology. Aerial photographs and their processing simplify and reduce the cost of large-scale land surveying and upgrading databases. As the software options and structures used for processing are different, their precision and workflow are different, too.

The current research is based on UltraCAM D frame aerial photos and investigates with two separate projects, to which extent software automation affects the accuracy of aerial triangulation (AT) (henceforth, first project) and the geometric quality of orthophoto mosaic (henceforth, second project). To increase the reliability of the analysis, the projects have been kept separate and are not interrelated.

For the first project, two adjusted photo blocks with automatic and manual AT were made. The photo blocks differ in their relative orientation. For the second project, three orthophoto mosaics were made: a mosaic processed with automatic steps, a mosaic processed with manual steps, and a mosaic processed with semi-automatic steps.

For both projects, aerial photos of UltraCAM D were used. The photos were taken on 7 May 2007 and processed with Photomod software.

The concept of the UltraCAM D is based on combining the image data of several CCD (Charge-coupled Device) sensors and different optical systems for generating one large image. The sensor unit of UltraCam D consists of eight independent cameras, so-called cones. Four of them create a large format panchromatic image. The other set of four cones is responsible for the multispectral channels of UltraCam D, i. e. red, green blue, and near infrared [1]. Each of sensors is the front end of a separate imaging module. It consists of the sensor, the sensor electronics, a high end analog/digital converter (ADC), a fast 
digital signal processor (DSP) and the IEEE 1394 data transfer unit [2]. UltraCam D digital camera sensor pixels are fixed; the objective is fixed with the focal length and thus always corresponds to a certain pixel size of square area on the ground Ground Sampling Distance (GSD) [3].

The input data of the AT are obtained through aerial photographing. The interior orientation elements for the digital aerial photographs are focal length, principal point, the size of the sensor, and pixel. Sensor size is determined by the number of pixels in the row and column direction. There are no moving parts in the focal plane of the digital camera and thus, the whole interior orientation is the same for all images; therefore, fiducial marks are missing, too. The distortion is negligible and the possible deformities are removed with camera calibration data [4].

The relative orientation combines photos, in the course of which geometric relationships at the moment of photographing are restored mathematically. During the relative orientation, tie and check points are added into overlapping areas between strips and adjacent photos. In the course of the relative orientation, the oblique parallax and angle location of the pictures are removed [5].

Block adjustment is mathematical approach, that determines the location and orientation of each image in coordinate system at the moment of photographing and in the process the point's coordinates are adjusted [6].

The UltraCAM D images of the current research are processed with photogrammetric software Photomod (version 5.1.). Photomod software enables to make orthophotos in different stages, each of which being automatic, manual or combined, in order to ensure the quality of the final product.

\section{Materials and methods}

In the first project, two aerial triangulated blocks were made. For both blocks 8 aerial photographs were used. The area of the photographs covers part of the city Tartu. The scale of the photos is 1:16.977 and the GSD is $15 \mathrm{~cm}$. Focal length $f=105.2 \mathrm{~mm}$. For the check points in external orientation of the AT and for the ground control points for the estimation of the geometric quality of the AT, 10 GPS-points in L-est'97 coordinate system were measured with Trimble R6.

For both blocks, coordinates of the check points were inserted and measured on the aerial photos for external orientation. Internal orientation was performed automatically. However, the blocks differ in relative orientation; for the first block it was made automatically and for the second one manually.

The effect of automation on AT was analyzed through geometric quality. For analysis, ground control points measured on the blocks were compared with GPS-points.

In order to make the three orthophoto mosaics for the second project, 20 aerial photographs with the parameters of those of the first project were used. For the AT and estimation of the geometric quality of the mosaics, 21 points were used. The points were also in the L-est'97 coordinate system and measured with GPS Trimble 5800.

The mosaics differ according to processing stage. The first mosaic was made fully automatically; for the second mosaic, the processing stages were manual, and as for the third mosaic, only the digital elevation model (DEM) was corrected manually.

For estimating the geometric quality of the mosaics, points coordinates measured on the mosaics were compared with GPS-coordinates. For increasing the accuracy of the interactive measurements, coordinate measurements were made three times in different magnification scales of mosaics. Average coordinates $\left(X_{\text {mean }}, Y_{\text {mean }}\right)$ were used for data processing. The Mean Root Square Error (RMS) was the indicator for geometric quality in both projects. The permitted size of the RMS was $0.45 \mathrm{~m}$ (3 times the pixel size).

\section{Results}

The part for analysis and results can be divided into two groups:

1) Analysis of the adjustment results of blocks in both projects, and the geometric quality of the AT in the first project;

2) Geometric quality of the mosaics in the second project.

The adjustment accuracy of the AT block in the projects is brought in Tables 1 and 2 and given in coordinate residuals, the maximum mean absolute, and RMS error in XY plane and Z plane in meters. The permitted RMS size here was 0.2 meters (GSD size) for each project and residuals larger than the permitted size were marked with "*".

The following symbols have been used in tables:

(1) - 1. project;

(2) - 2. project;

$\mathrm{X}, \mathrm{Y}, \mathrm{Z}$ - coordinates;

$\mathrm{Xm}, \mathrm{Ym}, \mathrm{Zm}$ - display coordinate value calculated from the all models;

$\mathrm{Xg}, \mathrm{Yg}, \mathrm{Zg}$ - check points coordinates; 
RMS - Mean Root Square Error, computed with formula 1:

$$
R M S=\sqrt{2} * E_{\text {mean }},
$$

where $E_{\text {mean }}$ is mean error calculated by formulas 2 and 3:

$$
\begin{aligned}
& E_{\text {mean }}^{x y}=\sqrt{2} * 0.5 p x l, \\
& E_{\text {mean }}^{z}=f / b^{*} E_{\text {mean }}^{x y},
\end{aligned}
$$

where $E_{\text {mean }}^{x y}-$ mean error in XY plane;

$E_{\text {mean }}^{z}$ - mean error in $\mathrm{Z}$ plane;

$P x l=G S D$

$f$ - focal length;

$b$ - survey bases on image scale $(\mathrm{mm})$. [7]

Table 1. The adjustment results of the automatic AT (in meters)

\begin{tabular}{|c|c|c|c|c|}
\hline $\mathrm{N}$ & $\mathrm{Xm}-\mathrm{Xg}$ & Ym-Yg & $\mathrm{Zm}-\mathrm{Zg}$ & Exy \\
\hline Limit: & 0.200 & 0.200 & 0.200 & 0.200 \\
\hline Mean absolute (1): & 0.167 & 0.193 & 0.137 & $0.271^{*}$ \\
\hline Mean absolute (2): & 0.123 & 0.210 & 0.046 & 0.249 \\
\hline RMS (1): & 0.169 & $0.228^{*}$ & 0.151 & $0.284 *$ \\
\hline RMS (2): & 0.146 & $0.274 *$ & 0.055 & $0.310 *$ \\
\hline Maximum (1): & $0.206^{*}$ & 0.186 & $0.222 *$ & $0.414^{*}$ \\
\hline Maximum (2): & $0.292 *$ & $0.630 *$ & 0.093 & $0.695^{*}$ \\
\hline
\end{tabular}

\begin{tabular}{lllll}
\hline $\mathrm{N}$ & $\mathrm{Xm}-\mathrm{Xg}$ & $\mathrm{Ym}-\mathrm{Yg}$ & $\mathrm{Zm}-\mathrm{Zg}$ & Exy \\
Limit: & 0.200 & 0.200 & 0.200 & 0.200 \\
\hline Mean absolute (1): & $0 . .138$ & $0 . .125$ & $0 . .301^{*}$ & $0 . .226^{*}$ \\
Mean absolute (2): & $0 . .022$ & $0 . .065$ & $0 . .000$ & $0 . .071$ \\
RMS (1): & 0.169 & 0.157 & $0.345^{*}$ & $0.230^{*}$ \\
RMS (2): & 0.024 & 0.069 & 0.000 & 0.073 \\
Maximum (1): & $0.276^{*}$ & $0.248^{*}$ & $0.526^{*}$ & $0.276^{*}$ \\
Maximum (2): & 0.032 & 0.098 & 0.000 & 0.098 \\
\hline
\end{tabular}

Table 2. The adjustment results of the manual AT (in meters)

From the adjustments results of the automatic AT (Table 1), we can see that the RMS computed from check points was within the permitted size for the second project, and the RMS error amounted to $0.073 \mathrm{~m}$. The RMS of the first project was $0.230 \mathrm{~m}$. The maximum residuals of the second project were less than $0.2 \mathrm{~m}$.

From the adjustments results of the manual AT (Table 2), we can see that the RMSs of both projects are larger than the permitted size. The RMSs are $0.284 \mathrm{~m}$ and $0.310 \mathrm{~m}$, respectively. Also the maximum residuals are mostly bigger than $0,2 \mathrm{~m}$, only the first projects maximum residual in $\mathrm{Y}$-coordinate was $0.186 \mathrm{~m}$.

Considering the adjustment results of the AT block, it was decided to analyze the geometric quality of both AT photo blocks of the first project. The results are given in Tables 3 and 4. For computing geometric quality, the Gauss formula for RMS error was used (Formula 4):

$$
m= \pm \sqrt{\frac{\Delta^{2}}{n}},
$$

where $m-\mathrm{RMS}$

$\Delta^{2}-$ sum of the square differences between GPS- and interactive measured coordinates;

$n$ - number of measurments. 
The accuracy of the self RMS $\left(m_{m}\right)$ was calculated from Formula 5 [8]:

$$
m_{m}= \pm \frac{m}{\sqrt{2 n}}
$$

Table 3. The accuracy calculations in automatic AT photo block

\begin{tabular}{|c|c|c|c|c|c|c|c|c|c|c|c|}
\hline \multirow{2}{*}{ Point } & \multicolumn{2}{|c|}{ GPS - coordinates } & \multicolumn{2}{|c|}{ Automatic AT block } & \multicolumn{2}{|c|}{ Differences (m) } & \multicolumn{2}{|c|}{ Squared differences } & \multirow{2}{*}{$\begin{array}{l}\text { Sum } \\
(\mathrm{m})\end{array}$} & \multirow{2}{*}{$\begin{array}{l}\text { Dislocation } \\
\text { (m) }\end{array}$} & \multirow{2}{*}{$\begin{array}{l}\text { Direction } \\
\text { of } \\
\text { dislocation }\end{array}$} \\
\hline & $\mathrm{X}(\mathrm{m})$ & $\mathrm{Y}(\mathrm{m})$ & $\mathrm{X}_{\text {mean }}(\mathrm{m})$ & $\mathrm{Y}_{\text {mean }}(\mathrm{m})$ & $\Delta \mathrm{X}$ & $\Delta \mathrm{Y}$ & $\Delta X^{2}$ & $\Delta \mathrm{Y}^{2}$ & & & \\
\hline 1 & 6475471.612 & 658406.448 & 6475471.941 & 658406.698 & -0.329 & -0.250 & 0.108 & 0.062 & 0.170 & 0.413 & SW \\
\hline 2 & 6473994,913 & 658227.886 & 6473994.387 & 658227.967 & 0.526 & -0.081 & 0.276 & 0.007 & 0.283 & 0.532 & NW \\
\hline 3 & 6474064.281 & 656959.468 & 6474064.311 & 656959.148 & -0.030 & 0.320 & 0.001 & 0.103 & 0.104 & 0.322 & SE \\
\hline 4 & 6473580.104 & 657831.786 & 6473580.563 & 657831.674 & -0.459 & 0.112 & 0.210 & 0.012 & 0.223 & 0.472 & SE \\
\hline \multirow[t]{7}{*}{5} & 6472666.155 & 658782.144 & 6472666.344 & 658782.356 & -0.189 & -0.212 & 0.036 & 0.045 & 0.081 & 0.284 & SW \\
\hline & & & & Sum: & -0.481 & -0.111 & 0.631 & 0.229 & 0.860 & 2.023 & \\
\hline & & & & Mean: & -0.096 & -0.022 & & & & 0.405 & \\
\hline & & & & Min: & -0.459 & -0.250 & & & & 0.284 & \\
\hline & & & & Max: & 0.526 & 0.320 & & & & 0.532 & \\
\hline & & & & & & $\mathrm{m}$ & 0.355 & 0.214 & 0.415 & & \\
\hline & & & & & & $\mathrm{m}_{\mathrm{m}}$ & 0.112 & 0.068 & 0.131 & & \\
\hline
\end{tabular}

Table 4. The accuracy calculations in manual AT photo block

\begin{tabular}{|c|c|c|c|c|c|c|c|c|c|c|c|}
\hline \multirow{2}{*}{ Point } & \multicolumn{2}{|c|}{ GPS -coordinates } & \multicolumn{2}{|c|}{ Manual AT block } & \multicolumn{2}{|c|}{ Differences (m) } & \multicolumn{2}{|c|}{ Squared differences } & \multirow{2}{*}{$\begin{array}{l}\text { Sum } \\
(\mathrm{m})\end{array}$} & \multirow{2}{*}{$\begin{array}{l}\text { Dislocation } \\
(\mathrm{m})\end{array}$} & \multirow{2}{*}{$\begin{array}{l}\text { Direction } \\
\text { of } \\
\text { dislocation }\end{array}$} \\
\hline & $\mathrm{X}(\mathrm{m})$ & $\mathrm{Y}(\mathrm{m})$ & $\mathrm{X}_{\text {mean }}(\mathrm{m})$ & $\mathrm{Y}_{\text {mean }}(\mathrm{m})$ & $\Delta \mathrm{X}$ & $\Delta \mathrm{Y}$ & $\Delta X^{2}$ & $\Delta \mathrm{Y}^{2}$ & & & \\
\hline 1 & 6475471.612 & 658406.448 & 6475471.757 & 658406.517 & -0.145 & -0.069 & 0.021 & 0.005 & 0.026 & 0.161 & SW \\
\hline 2 & 6473994.913 & 658227.886 & 6473994.923 & 658227.960 & -0.010 & -0.074 & 0.000 & 0.005 & 0.006 & 0.075 & SW \\
\hline 3 & 6474064.281 & 656959.468 & 6474064.224 & 656959.519 & 0.057 & -0.051 & 0.003 & 0.003 & 0.006 & 0.076 & NW \\
\hline 4 & 6473580.104 & 657831.786 & 6473580.168 & 657831.762 & -0.064 & 0.024 & 0.004 & 0.001 & 0.005 & 0.068 & $\mathrm{SE}$ \\
\hline \multirow[t]{7}{*}{5} & 6472666.155 & 658782.144 & 6472666.133 & 658782.191 & 0.022 & -0.047 & 0.000 & 0.002 & 0.003 & 0.052 & NW \\
\hline & & & & Summa & -0.139 & -0.218 & 0.631 & 0.229 & 0.860 & 0.432 & \\
\hline & & & & Keskmine & -0.028 & -0.044 & & & & 0.086 & \\
\hline & & & & Miinimum & -0.145 & -0.074 & & & & 0.052 & \\
\hline & & & & Maksimum & -0.057 & 0.024 & & & & 0.161 & \\
\hline & & & & & & $\mathrm{m}$ & 0.076 & 0.056 & 0.094 & & \\
\hline & & & & & & $\mathrm{m}_{\mathrm{m}}$ & 0.024 & 0.018 & 0.030 & & \\
\hline
\end{tabular}

As can be seen from Tables 3 and 4, the minimum coordinates difference in $\mathrm{x}$-axis was $0.030 \mathrm{~m}$ and maximum $0.526 \mathrm{~m}$, in $\mathrm{y}$-axis minimum was $0.081 \mathrm{~m}$ and the maximum $0.320 \mathrm{~m}$ for the automatic project. For the manual project, in $\mathrm{x}$-axis the minimum was $0.010 \mathrm{~m}$ and the maximum $0.057 \mathrm{~m}$, in y-axis $0.024 \mathrm{~m}$ and $0.074 \mathrm{~m}$. The dislocations of the automatic AT block differed exponentially from the dislocations of the manual block. The dislocations values are shown in Figure 1. 


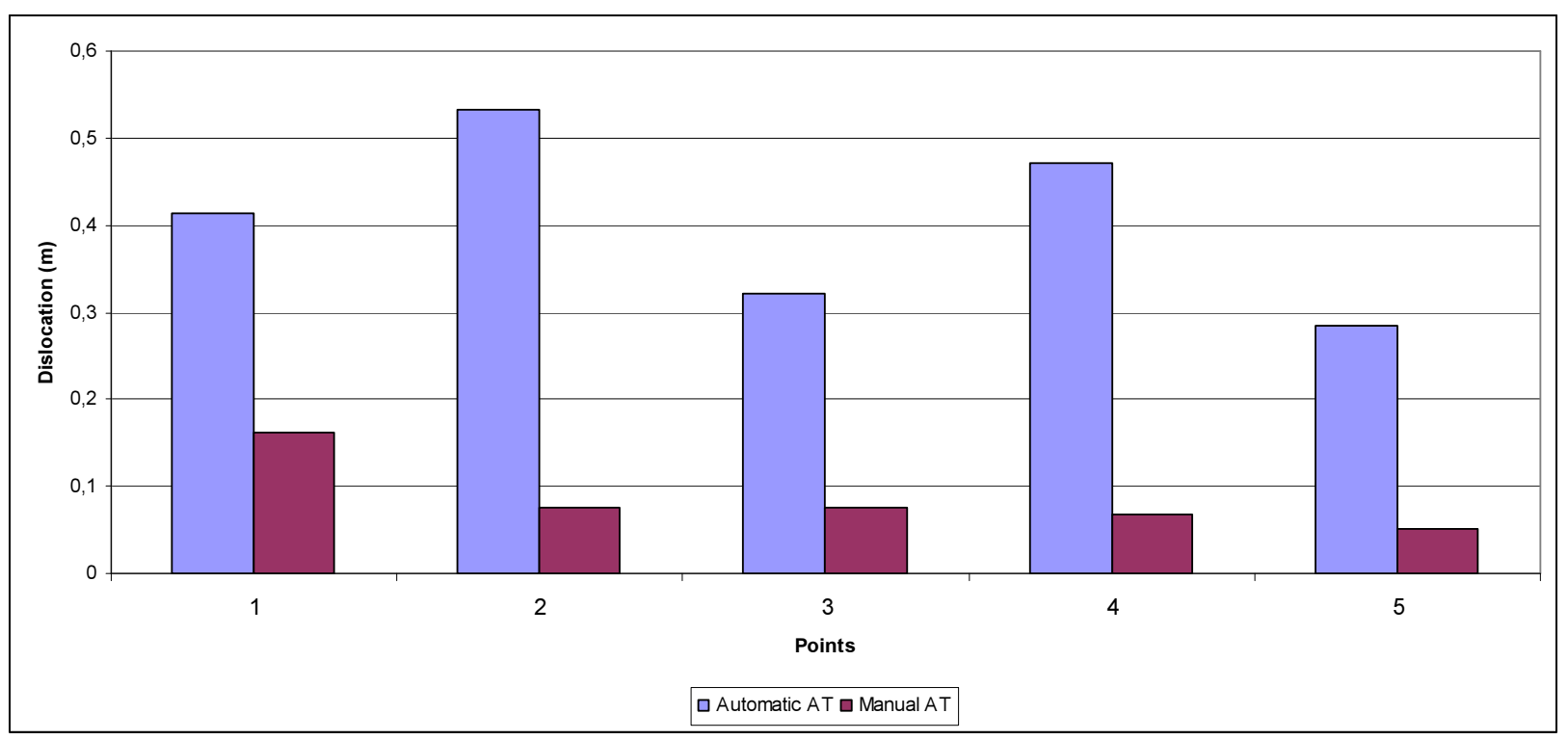

Fig. 1. Dislocations of AT blocks according to coordinate points

The maximum dislocation of the manual AT was $0.161 \mathrm{~m}$ (point 1) and the maximum of the automatic AT was $0.532 \mathrm{~m}$ (point 2). 3 points of the automatic AT (points $1,3,5)$ were within the permitted size $(0,45 \mathrm{~m})$. In the manual AT, all points were within the permitted size.

The RMSs of the projects differ significantly, too (Fig. 2), although the RMSs were all within the permitted size.

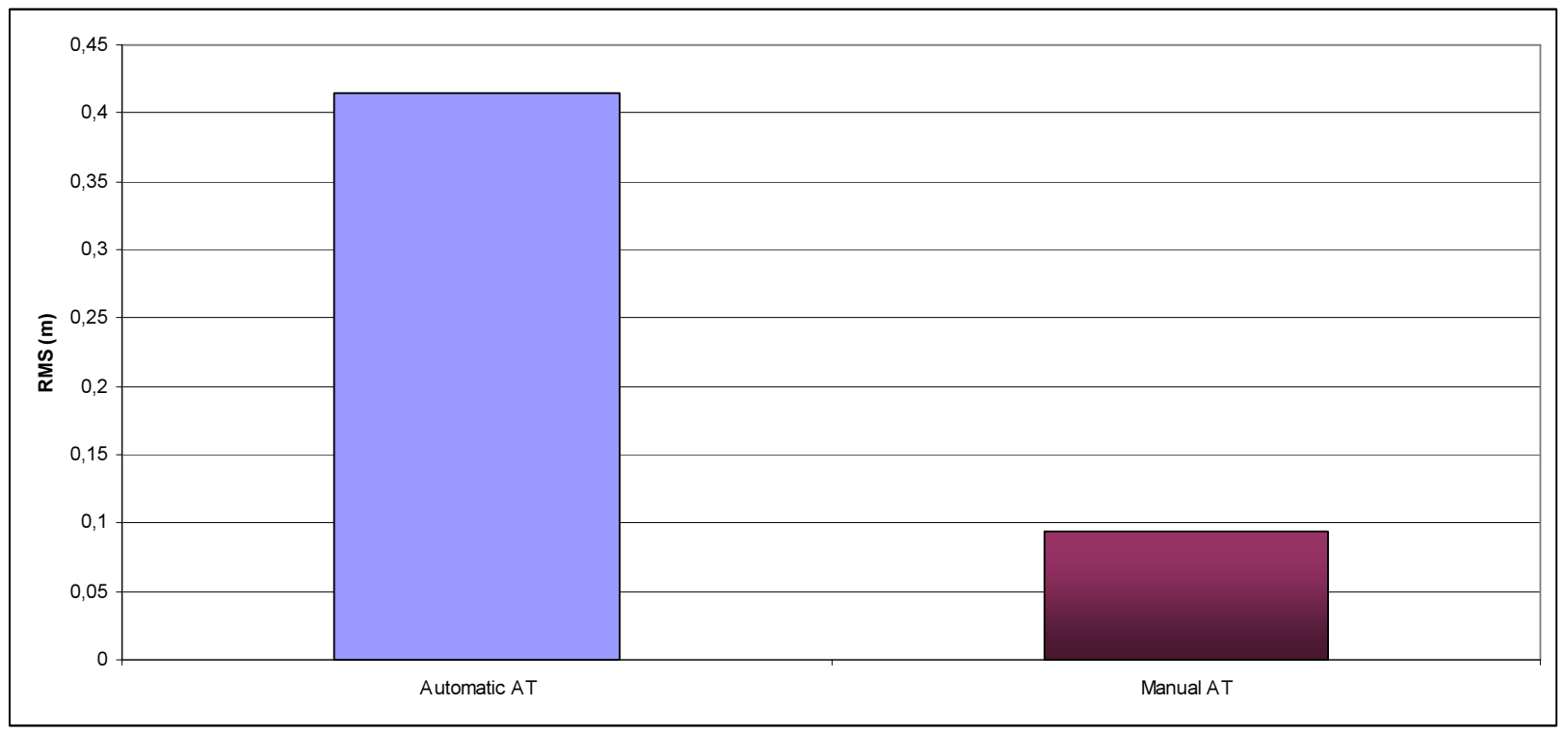

Fig. 2. RMS errors of AT blocks

From Figure 2 we can see that the RMS of the automatic AT was 0.415 and the manual AT RMS was $0.094 \mathrm{~m}$. The RMSs were calculated in turn with error 0.131 and 0.030 meters.

The second group of the research involved the analysis of the geometric quality of the mosaics. The GPS-coordinates were compared with mosaic points on the coordinates and the dislocations and RMS of mosaics were computed. The RMS was computed with Formula 4. The results are brought in Figure 3 and 4. Figure 3 shows the dislocations of the ground control points and Figure 4 the RMSs of the mosaics. 


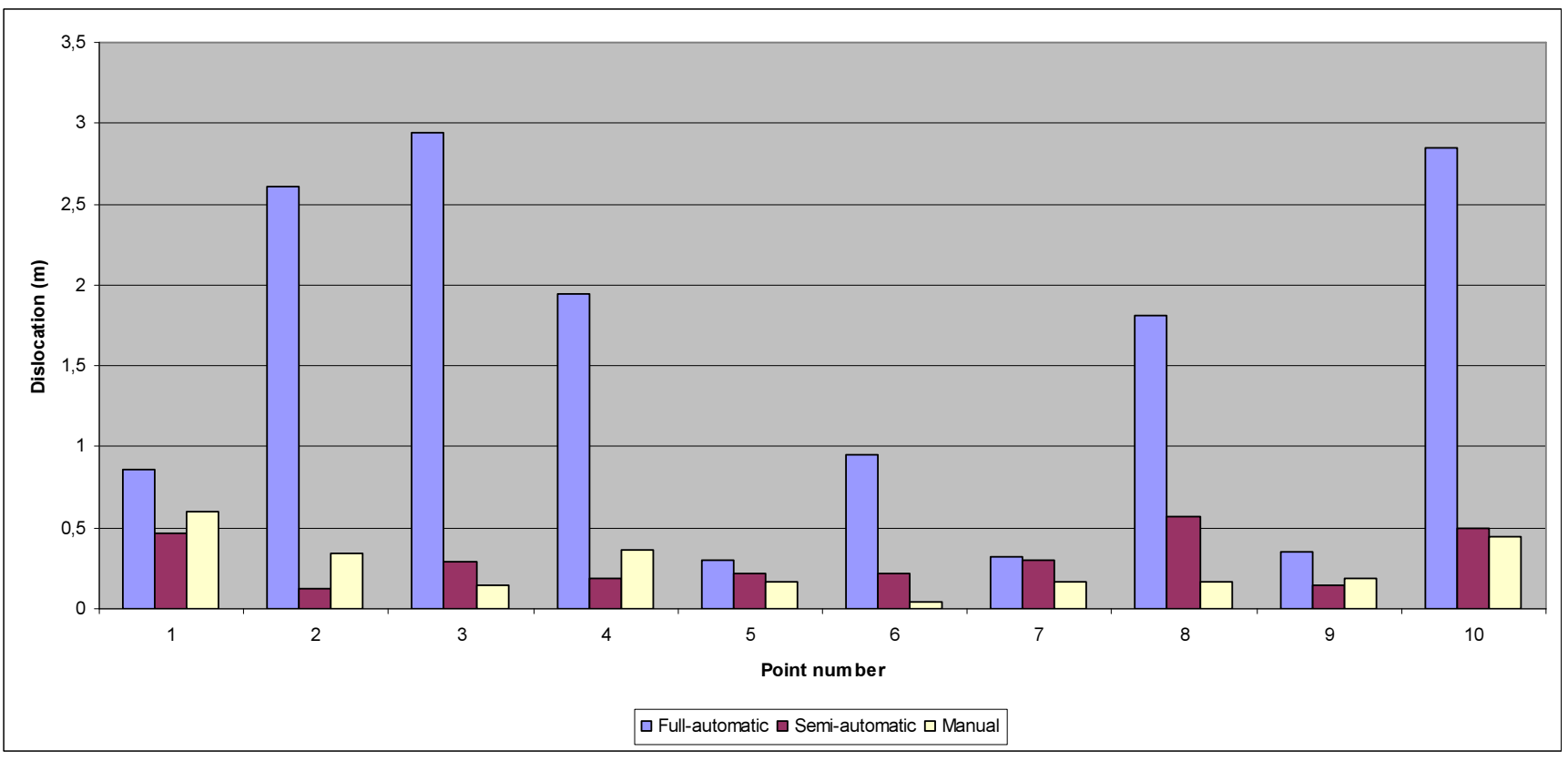

Fig. 3. Sizes of dislocation

From Figure 3 we can see a clear difference in the dislocations of the automatically made mosaic with dislocations differing according to mosaics. The maximum dislocation of the automatic mosaic was $2.937 \mathrm{~m}$ (point 3) and the minimum dislocation was $0.297 \mathrm{~m}$ (point 5). The maximum dislocation of the semi-automatic mosaics was $0.566 \mathrm{~m}$ (point 8 ) and the minimum was $0.125 \mathrm{~m}$ (point 2). The maximum dislocation of the manual mosaic was $0.596 \mathrm{~m}$ (point 1) and the minimum was $0.043 \mathrm{~m}$ (point 6). From results we can see, that the biggest dislocations were in points 2,3 and 10 for automatically made mosaic, but dislocations in the same points of other two mosaic were not big and didn't differ from other dislocations.

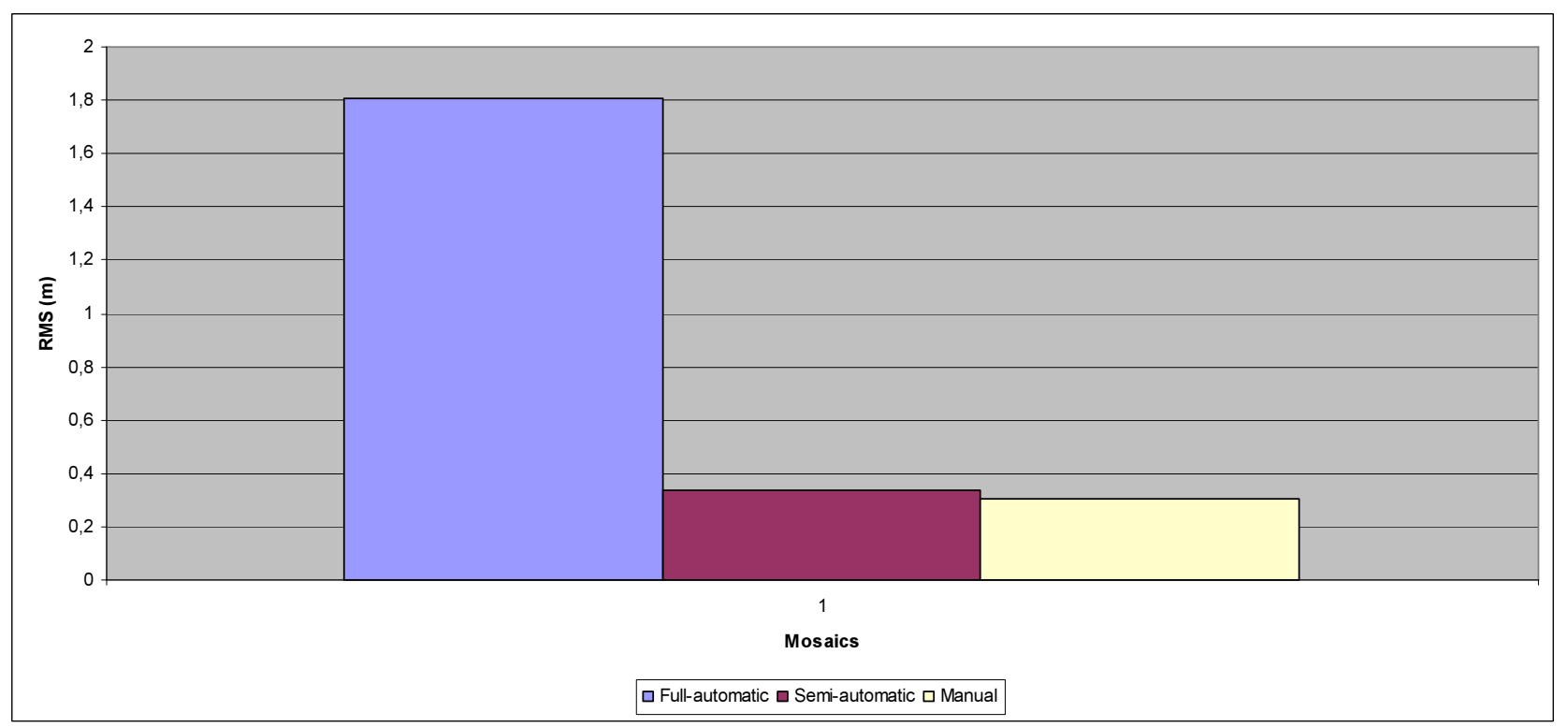

Fig. 4. RMS of the mosaic

From Figure 4 we can see that the RMS of the automatic mosaic is 4 times larger than the permitted size, the RMS value being $1.805 \mathrm{~m}$. The RMSs of the semi-automatic and manual mosaics are both within the permitted size, the RMSs being $0.335 \mathrm{~m}$ and $0.308 \mathrm{~m}$, respectively. The accuracy of the RMSs themselves was $0.404 \mathrm{~m}$ in the automatic mosaic, $0.075 \mathrm{~m}$ in the semi-automatic mosaic, and 0.069 in the manual mosaic. 


\section{Conclusions}

From the analysis of the AT geometric accuracy of the first project based on UltraCAM D aerial photographs we can see that it is more precise if the AT is processed manually, as the RMS was $0.094 \mathrm{~m}$. The RMS of the automatically processed AT was $0.415 \mathrm{~m}$. From the results we can conclude that the automatically processed relative orientation affects the whole accuracy of the AT. Although the RMSs of the both triangulated blocks were within the permitted size $(0.45 \mathrm{~m})$, nevertheless, the manually processed relative orientation proved to be more precise regardless of the fact that the values of the RMS computed from block adjustment were in the case of the automatic AT higher than in the case of the manual AT.

The analysis of the second project showed that software automation affects the geometric quality of the orthophoto mosaic. From the results we can see that the manually processed mosaic is more precise. We can also get precise results for mosaics processed with automatic AT and manually corrected DEM (so-called semi-automatic mosaic). The RMSs for the first two mosaics were $0.308 \mathrm{~m}$ and $0.335 \mathrm{~m}$, respectively, which were calculated in turn with error $0.075 \mathrm{~m}$ and $0.069 \mathrm{~m}$. The RMS of the fully automatically processed mosaic was $1.805 \mathrm{~m}$ (calculated in turn with error $0.404 \mathrm{~m}$ ), which was higher than the permitted value.

\section{Acknowledgements}

This study is supported by the Estonian Science Foundation grant ETF 8749: Determination of height reference frame on the Estonian coastal sea using water lever monitoring and laser scanning data.

\section{References}

[1] Haest, B.; Biesemans, J.; Horsten, W.; Everaerts, J. 2009. Radiometric calibration of digital photogrammetric camera image data, in ASPRS 2009 Annual Conference Baltymore, Maryland. [http://publications.vgt.vito.be/documents/BH/Haest_2009_ASPRS\%20Proceedings\%20Baltimore\%20USA_adj.pdf] (05.12.2013).

[2] Krüpfl, M.; Kruck, E.; Gruber, M. 2004. Geometric calibration of the digital large format aerial camera UltraCamD. Istanbul, Turkey.

[3] Liba, N. 2005. Fotogramm-meetria alused. Tartu. Eesti Põllumajandusülikool 303: 110-111.

[4] Aber, J. S.; Marzolff, I.; Ries, J. 2010. Small-Format Aerial Photography: Principles, Techniques and Applications. ISBN: 978-0-444-53260-2

[5] Kresse, W.; Danko, D. M. 2012. Springer handbook of geographic information. Springer. ISBN: 978-3-540-72680-7. http://dx.doi.org/10.1007/978-3-540-72680-7

[6] Jacobsen, K. 1997. Operational blokk adjustment without control points. [http://www.ipi.uni-hannover.de/uploads/tx_tkpublikationen/jac_97_cpoints.pdf] (19.05.2013)

[7] Accuracy control at various stages of photogrammetric processing in PHOTOMOD system. Racurs, Moscow, Russia 2012. [http://www.racurs.ru/?page=586] (03.06.2013).

[8] Randjärv, J. 1997. Geodeesia I osa. Tartu. 360. 